1 Universidade de São Paulo (USP), Faculdade de Arquitetura e Urbanismo (FAU) - São Paulo (SP), Brasil.

Orcid: https://orcid. org/0000-0002-1085-

6238

erminia@usp.br

2 Universidade de São Paulo (USP), Faculdade de Filosofia Letras e Ciências Humanas (FFLCH) - São Paulo (SP), Brasil. Orcid: https://orcid. org/0000-0003-46060378

paolocolosso@usp.br

3 Universidade Federal do $A B C$ (UFABC), Centro de Engenharia, Modelagem e Ciências Sociais Aplicadas (Cecs) - Santo André (SP), Brasil.

Orcid: https://orcid. org/0000-0002-1091-

2156

francisco.comaru@ufabc.

edu.com

\section{Um projeto para as cidades brasileiras e o lugar da saúde pública}

\author{
A project for Brazilian cities and the place of public health
}

Erminia Maricato', Paolo Colosso $\mathbf{2}^{\mathbf{2}}$ Francisco de Assis Comarú ${ }^{\mathbf{3}}$

DOI: $10.1590 / 0103-110420185315$

RESUMO $\mathrm{O}$ artigo reconstituiu marcos fundamentais da urbanização brasileira, com o objetivo de argumentar pela necessidade de construção social de um projeto para as cidades do Brasil capaz não apenas de trazer formulações intelectuais progressistas, mas também, sobretudo, de convergir forças sociais em torno de uma agenda que vise à consecução de cidades mais justas em termos socioespaciais, ambientalmente sustentáveis, economicamente dinâmicas e culturalmente plurais. Para tanto, em um primeiro momento, tratam-se aspectos estruturais da urbanização brasileira ao longo do século XX, bem como salientam-se experiências virtuosas de governos locais no fim dos anos 1980 e 1990. Em seguida, analisam-se contradições engendradas nos anos 2000 e, por fim, elencam-se algumas das primeiras propostas minimamente consensuadas até aqui.

PALAVRAS-CHAVE Urbanização. Planejamento de cidades. Brasil. Distribuição espacial da população.

ABSTRACT The article reconstructs fundamental milestones of Brazilian urbanization, with the objective of arguing for the need of social construction of a project for our cities, capable not only of making progressive theoretical formulations, but also, above all, of converging social forces around an agenda aimed at achieving cities that are more just socio-spatially, environmentally sustainable, economically dynamic and culturally plural. For that, we first deal with the structural aspects of Brazilian urbanization throughout the 20th century and highlight virtuous experiences of local governments in the late 1980s and 1990s. Then, we analyze contradictions engendered in the 2000 s and, finally, we list some of the first proposals minimally agreed upon so far.

KEYWORDS Urbanization. City planning. Brazil. Residence characteristics. 


\section{Introdução}

Vivemos um período de transição no mundo e no Brasil. As mudanças estão em curso e serão feitas com ou sem a participação das forças democráticas da sociedade. Garantir um futuro com mais justiça social, econômica, ambiental, territorial e urbana depende da nossa participação.

Dez anos após o colapso financeiro de 2008, cujos ônus sociais ainda são sentidos pelos quatro cantos do globo, poucas saídas foram postas para além do receituário neoliberal de austeridade fiscal com direitos sociais, perdão de dívidas de grandes empresas e subserviência aos ditames do mercado financeiro. Não apenas sua eficácia na recuperação econômica é discutível como também, sobretudo, tais medidas recolocam os países nos descaminhos da concentração de renda e aumento de abismos sociais, como já bem descreveram Stiglitz ${ }^{1}$ e Piketty ${ }^{2}$.

Desde os anos 1980, nosso país vive, por sua vez, um processo de internacionalização, desindustrialização e financeirização que nos leva ao retorno à condição de agroexportador - grãos, carnes, celulose, minérios e etanol. A participação da indústria no Produto Interno Bruto (PIB) do País decresceu a níveis das primeiras décadas do século passado ${ }^{3}$.

No que diz respeito às cidades, houve transformações positivas e negativas. As metrópoles que mais cresceram nos últimos 30 anos estão nas regiões Centro-Oeste, Norte, Nordeste. De modo geral, o fenômeno do crescimento intenso atingiu mais as cidades de porte médio que apresentaram taxas mais elevadas que as das metrópoles, em população e em PIB. Percebeu-se um processo notável de dispersão urbana e uma nova onda de especulação fundiária para além dos grandes centros, sobretudo nos anos de crescimento econômico entre os anos 2000 e meados de 2010.

Nesse período, a dinâmica populacional mudou, em grande parte, devido ao processo de urbanização, avanço do saneamento e atendimento à saúde: diminuiu a mortalidade infantil e a taxa de natalidade; aumentou a expectativa de vida. As migrações, que tinham como destino predominante a região geoeconômica centro-sul, reorientaram-se para o Centro-Oeste, o Norte e o Nordeste. Todas as regiões cresceram mais economicamente do que a Sudeste, embora esta ainda se conserve como pólo mais dinâmico do País.

Essas são algumas das razões fundamentais que justificam a necessidade de repensar coletivamente um projeto para as cidades do Brasil capaz de convergir forças sociais progressistas em torno de uma agenda que vise à consecução de cidades mais justas em termos socioespaciais, ambientalmente sustentáveis, economicamente dinâmicas e culturalmente plurais.

Dessa forma, o objetivo deste artigo é avançar em pontos centrais desse diagnóstico, mas também apontar algumas linhas de força para esse projeto de médio e longo prazo. Nesta perspectiva, em um primeiro momento, reconstituímos aspectos estruturais da urbanização brasileira ao longo do século XX e salientamos experiências virtuosas de governos locais progressistas no fim dos anos 1980 e 1990. Em seguida, analisamos contradições engendradas nos anos 2000 e, por fim, elencamos algumas das primeiras propostas minimamente consensuadas até aqui.

\section{Aspectos estruturais da urbanização brasileira e experiências democráticas pós-ditadura}

Em nosso país, urbanização e industrialização se deram, tardiamente, durante o século XX. Entre 1940 e 1970, o Brasil cresceu a taxas de, aproximadamente, $7 \%$ ao ano. Nesse período, a população urbana passou de 12,9 milhões para 52 milhões. Sem acesso ao mercado residencial formal e sem acesso 
às políticas públicas urbanas, uma imensa massa de migrantes se instalou como pôde, especialmente nos grandes centros, com parcos recursos, constituindo uma mão de obra farta e barata. Esta teve um papel funcional para o processo de acumulação de base industrial.

O resultado desse processo foi a construção de gigantescas periferias ilegais e predatórias à vida dos trabalhadores e ao meio ambiente. À industrialização dos baixos salários correspondeu a urbanização dos baixos salários ${ }^{4}$. Em contraposição, outra cidade, mais visível, hegemônica, restrita, concentrou os investimentos públicos e privados em favor de um mercado imobiliário altamente especulativo e de luxo, promovendo assim a abissal desigualdade social que reafirma, parcialmente, a herança de quatro séculos de exploração do trabalho escravo. Nos anos 1980 e 1990, com o impulso das lutas pela redemocratização do País, em que pese a ausência de investimentos públicos devido a políticas de austeridade fiscal e forte presença do Fundo Monetário Internacional (FMI) e Banco Mundial, muitas cidades viveram experiências inovadoras em governos locais, conhecidos posteriormente como 'prefeituras democrático-populares'. Movimentos sociais, pesquisadores, professores, Ongs e profissionais se organizaram no denominado Movimento pela Reforma Urbana, cujas propostas - sistematizadas nos Fóruns da Reforma Urbana - faziam parte das Reformas de Base. Tratava-se de uma grande convergência que, desde o início dos anos 1960, buscava superar o subdesenvolvimento e a desigualdade social no Brasil.

Novos personagens ligados às lutas urbanas criaram uma agenda nacional de propostas. Entre os muitos projetos implementados, estavam os Centros Integrados de Educação Pública (Cieps), concebidos por Darcy Ribeiro enquanto Secretário de Educação do Governo de Leonel Brizola no Rio de Janeiro, o Orçamento Participativo, com repercussão e acolhida no mundo todo, a urbanização de favelas e áreas precárias, a assistência técnica à habitação social, os corredores de ônibus 5 . Além disso, um conjunto impressionante de leis se seguiram à Constituição Federal de 1988: Estatuto da Cidade, Leis de Consórcio Públicos, Lei do Fundo de Habitação de Interesse Social, Lei do Saneamento Básico, Lei da Mobilidade Urbana, Lei dos Resíduos Sólidos e Estatuto da Metrópole, entre outras. A Emenda Popular Constitucional de Reforma Urbana constituiu um ponto alto dessa trajetória, pois logrou incluir, na Constituição de 1988, a Função Social da Cidade e a Função Social da Propriedade; e, mais tarde, na Reforma Constitucional de 2000, no art. $6^{\circ}$, o Direito à Moradia.

\section{Anos 2000: crescimento econômico, desigualdade e impactos na saúde}

A partir de 2002, com o início do ciclo de governos federais Lula e Dilma, houve a implementação de políticas públicas visando diminuir as desigualdades sociais no Brasil sem, no entanto, tocar nos fundamentos mais estruturantes e seculares da nossa formação social. Essas políticas implementadas pelos dois governos Lula (2003-2010) e pelo primeiro governo Dilma Rousseff (2011-2014) fizeram a diferença para milhões de brasileiros. Uma das maiores conquistas desse período foi, talvez, retirar o Brasil do Mapa da Fome da Organização das Nações Unidas (ONU) ${ }^{6}$. Entre 2002 e 2012, o Brasil reduziu em $82 \%$ sua população de desnutridos, o que significou 36 milhões de pessoas. Entre os projetos que mais contribuíram para combater a fome, está o Programa Bolsa Família, uma política social de transferência de renda para a mãe de família com a condição de que seus filhos frequentem escolas. Ao lado desse programa, outros fatores contribuíram para erradicação da fome e para ampliar o mercado interno de consumo popular, o que ajudou a criar 22 milhões de empregos. 
Entre 2002 e 2015, o aumento real do salário mínimo foi de $77 \%$. Outros projetos importantes mudaram as condições de vida dos brasileiros, como o Luz para Todos, que levou energia elétrica para 3,14 milhões de famílias; o Programa de Fortalecimento da Agricultura da Agricultura Familiar (Pronaf) e, ligado a ele, o Programa de Aquisição de Alimento (PAA)3 ; o Programa de Construção de Cisternas na região do semiárido, que apoiou a construção de 1,2 milhão de cisternas. Já o Programa Mais Médicos, resultante de uma parceria com o governo cubano, levou médicos a regiões remotas do País. É importante lembrar também que o orçamento federal para educação cresceu $218 \%$ entre 2002 e 2014 e que o número de estudantes universitários cresceu de 3,5 milhões para 7,1 milhões. $\mathrm{O}$ acesso de negros, índios e brancos pobres modificou o perfil das universidades ${ }^{7}$.

Em relação à política para as cidades, entretanto, houve forte regressão, apesar da criação do Ministério das Cidades com seu Conselho Nacional, das Conferências participativas Municipais, Estaduais e Federais, um arcabouço legal urbanístico inovador. Por mais contraditório que possa parecer, essa regressão se dá exatamente, e certamente por isso mesmo, quando o governo federal retoma em escala significativa, depois de décadas, o investimento em infraestrutura e moradia. Grandes empreiteiras, incorporadores imobiliários, proprietários de terra e capital financeiro orientaram muito do que seria construído, mas especialmente onde seria construído. Em termos gerais, a localização de conjuntos habitacionais, o traçado dos metrôs, o traçado dos Veículos Leves Sobre Trilhos (VLT) ou dos corredores de ônibus obedecem à lógica do rentismo fundiário/imobiliário: agregam 'valor' ao metro quadrado no entorno das propriedades daqueles que pressionam o poder público. As cidades, pouco a pouco, retomaram o rumo do aprofundamento da desigualdade, sucumbindo à ampliação das forças conservadoras no interior da política de coalizão. Esse conjunto de forças que tomaram o comando das cidades no contexto dos megaeventos e do pós-crise de 2008 incluem obviamente os executivos e legislativos municipais, a quem cabe a competência constitucional sobre a regulação do uso e da ocupação do solo urbano. Proprietários locais, algumas empresas nacionais e poucos parceiros internacionais foram os maiores ganhadores com esse grande movimento.

Antes de discorrer sobre os dados que comprovam as grandes mudanças pelas quais passaram as cidades em um período do 'boom imobiliário' no Brasil, é preciso buscar explicações para essa mudança que foi apresentada aqui sem nuances. $O$ que mudou entre o cenário das cidades que viveram a democracia direta do orçamento participativo nos 1990 para o cenário das cidades dominadas pelos capitais ligados ao mercado fundiário e imobiliário?

As forças sociais que na década de 1980 conquistaram o novo ciclo democrático foram crescentemente absorvidas pela institucionalização da política centrada, cada vez mais, na disputa eleitoral. A força oriunda da organização capilarizada, situada em bairros e sindicatos, esmaeceu. O repertório da luta pela Reforma Urbana comprova essa afirmação. Nos anos 2000, o foco estava na aprovação de novas leis, novos conselhos participativos, novos planos diretores, novos órgãos de governo. A correlação de forças também apresenta uma mudança que passa despercebida pelos partidos de esquerda ou progressistas (de modo geral). Apenas em 2013, com os protestos de junho, ganha visibilidade a quebra da hegemonia do Partido dos Trabalhadores nos eventos de rua.

Passemos aos dados entretanto. Entre 2009 e 2015, os setores imobiliários e da construção civil alavancam o PIB. O governo federal tentou enfrentar a crise internacional de 2008 com investimentos em obras e desonerações fiscais como incentivo para o consumo interno. Nesse período, as cidades receberam aproximadamente $\mathrm{R} \$ 800$ 
bilhões de investimentos para produção de moradias provenientes do Fundo de Garantia Por Tempo de Serviço (FGTS), Sistema Brasileiro de Poupança e Empréstimo (SBPE) e Orçamento Geral da União (OGU) ${ }^{8}$. O Programa de Aceleração do Crescimento (PAC) da Mobilidade investiu aproximadamente R $\$ 90$ bilhões em obras, muitas das quais relacionadas com os Megaeventos Copa e Olimpíadas 9 . No entanto, o mercado aquecido elevou o valor dos imóveis em uma proporção de 2 a 3 vezes acima da inflação média no período, obviamente também muito acima da valorização dos salários. O caso de São Paulo é gritante: o valor de venda dos imóveis aumentara $235,32 \%$ entre janeiro de 2008 e julho de 2018, permanecendo estável mesmo nos últimos dois anos, de recessão e estagnação. No Rio de Janeiro não foi diferente: nos últimos dez anos, o valor de venda acumula uma alta de $229 \%$, segundo o índice Fipezap; nesse mesmo período, a inflação (Índice Nacional de Preços ao Consumidor Amplo - IPCA) acumulada é de 84,28\%.

A prioridade dada ao automóvel pela política de desoneração tributária fez com que o número de veículos individuais aumentasse desproporcionalmente ao crescimento populacional, impondo um alto custo econômico, social, ambiental e na saúde. Reforçou-se o paradigma do denominado 'rodoviarismo'. Em 2014, os investimentos públicos com mobilidade eram estimados em $\mathrm{R} \$ 12,1$ bilhões por ano, sendo $77 \%$ relativos ao uso dos modos individuais, sobretudo destinados à manutenção de vias e em acidentes. Entretanto, o transporte individual não é o que viabiliza a maior proporção de viagens: essas se dividem entre $36 \%$ a pé, $4 \%$ de bicicleta, mais $29 \%$ em transporte coletivo e $31 \%$ em transporte individual. Em termos de distância percorrida, $60 \%$ do total refere-se ao transporte coletivo, $35 \%$ em transporte individual (carro e moto) ${ }^{10}$. No que diz respeito à emissão de poluentes locais - monóxido de carbono, óxidos de nitrogênio e enxofre -, os veículos emitem 528 mil toneladas por ano; desse total, $59 \%$ são emitidos por automóveis, enquanto cerca de $21 \%$ corresponde aos ônibus. Tais números mostram que o automóvel seguiu como uma prioridade indiscutível em termos de investimentos públicos, ao mesmo tempo que gera o maior impacto ambiental e na saúde pública. Além disso, não é o meio mais utilizado pela população, tampouco é mais eficiente em termos energéticos e de deslocamento. Essa ainda é uma tendência se percebermos que, no total de viagens, a participação do transporte coletivo caiu $1,5 \%$ entre 2003 e 2014; já o transporte individual aumentou $2,2 \%{ }^{10}$.

A ausência de investimentos massivos e permanentes nos sistemas de transportes públicos, coletivos e de alta e média capacidade agravam as condições ambientais e a saúde da população. Pesquisas cientificas, a partir de monitoramento de parâmetros ambientais e sanitários em dias de paralisação e greve dos sistemas de transporte, revelam, por exemplo, que os benefícios do metrô para a saúde pública, em uma metrópole como São Paulo, valorados apenas com base na mortalidade evitada de idosos e considerando apenas o efeito do Material Particulado MP 10 (portanto subdimensionados e subvalorados), representa uma economia anual de cerca de US $\$ 11$ bilhões, valor suficiente para construção de cerca de $73 \mathrm{~km}$ de linhas de metrôn'

Nesse sentido, o investimento em transporte público de massa, como o sistema de metrô, que possui um custo de implantação médio de US\$ 150 milhões $/ \mathrm{km}$, deve ser considerado não apenas viável, mas também sustentável e, por isso, prioritário na construção de uma agenda urbana que internalize os benefícios ambientais e sociais aos custos finais"1.

Os investimentos e a regulação pública na área da mobilidade urbana têm incentivado um aumento dos problemas gerais para a população (poluição atmosférica, por exemplo) e o aumento de problemas relacionados com as abissais desigualdades e iniquidades. 
Somente na cidade de São Paulo, por exemplo, estima-se que são perdidos, em média, de 1,5 a 2 anos de vida em função da poluição atmosférica. Deslocar-se diariamente na metrópole paulista equivale a fumar quatro cigarros por dia ${ }^{12}$. A análise sobre os dados de poluição em agravos em saúde nas cidades brasileiras mostra que nos defrontamos com um quadro de extremas externalidades negativas e injustiças socioambientais, na medida em que os custos da degradação ecológica e dos agravos em saúde não são pagos pelos responsáveis pela sua geração"

A respeito das iniquidades, sabe-se que São Paulo e Nova Iorque são as cidades que possuem a maior frota de helicópteros do mundo. Na capital paulista, estima-se que ocorram mais de 20 mil viagens por ano, tendo como origem/destino a Região Metropolitana de São Paulo (RMSP) em mais de 500 aeronaves. A presença desse tipo de veículos nas cidades gera inúmeros impactos, entre os quais, atmosféricos e sonoros. Em 2001, estimava-se que havia 109 helipontos na cidade; e, em 2010, eram cerca de 400, muitos dos quais operando ilegalmente, sem licença do poder público local13. As disparidades chegam a tal ponto que, na região da rua Funchal na Vila Olímpia, por exemplo, havia 25 helipontos enquanto esta mesma região contava com 24 paradas de ônibus locais ${ }^{13}$.

Vale lembrar que sobre veículos como helicópteros, lanchas e iates não incidem impostos ordinários como o Imposto sobre Propriedade de Veículos Automotores (IPVA), em um flagrante incentivo ao privilégio de classes, de um lado, e desprezo pela noção e pela prática de justiça social e ambiental, de outro. Para enfrentar o problema da extrema pobreza e miséria urbana, será necessário enfrentar os injustificáveis privilégios que alimentam e perpetuam as iniquidades, ou seja, as desigualdades evitáveis, injustas e estruturais.

Alinhados ao primado do rodoviarismo e do mercado imobiliário dirigido para poucos, governos municipais promoveram, com a ajuda da flexibilização da regulação fundiária, um radical espraiamento urbano, em especial nas cidades de porte médio (mas observado também tanto nas metrópoles, quanto em cidades menores), aumentando os custos da urbanização, favorecendo a especulação com terras, ampliando as viagens diárias. Essa dinâmica lançou os trabalhadores de baixa renda para a periferia da periferia em bairros resultantes da autoconstrução ou de conjuntos habitacionais de promoção público/privada, altamente subsidiados.

No que se refere a indicadores de saneamento e saúde, em que pese os desafios gigantescos, podemos observar avanços, sobretudo entre 2004 e meados de 2010: no abastecimento de água potável, no esgotamento sanitário, no manejo de resíduos sólidos, na drenagem e manejo de águas pluviais urbanas. Um dos principais instrumentos para viabilização do saneamento básico no Brasil fora o Plano Nacional de Saneamento Básico (Plansab) aprovado em 2013.

As atividades de planejamento do setor foram ampliadas naqueles anos por meio de inúmeros planos municipais de saneamento e investimentos massivos associados ao PAC. No entanto, nota-se que as disparidades e desigualdades inter-regionais mantêm-se, apesar dos investimentos. Ainda há muito o que realizar para garantir o acesso à água potável para todos os brasileiros. $\mathrm{O}$ acesso à rede geral, ou poço, ou nascente com canalização cresceu nos domicílios urbanos de 95\% para $97 \%$ em 2000 e 2013 no Brasil ${ }^{14}$. As regiões Nordeste e Norte avançaram consideravelmente nas últimas duas décadas. Na primeira, em 2000, 88\% dos domicílios urbanos apresentam condição de acesso à água potável por rede de distribuição, passando para $95 \%$ em 2006 e chegando a $94 \%$ em $2013^{14}$.

Com relação ao acesso ao serviço de esgotos sanitários com tratamento, o Índice de Esgoto Tratado Referido à Água Consumida mostra que, em 1998, cerca de 19\% do esgoto gerado do País era tratado. Em 2013, esse indicador passou para cerca de 
$39 \%$ do total de esgoto gerado ${ }^{\mathbf{1 4}}$. Os valores extremos mostram, por sua vez, como o País é marcado por fortes desigualdades regionais. $\mathrm{Na}$ região Centro-Oeste, o índice de esgoto tratado referido à água consumida equivalia a 11\% em 1998 e a $46 \%$ em 2013; já na região Sudeste, o mesmo indicador equivalia a $22 \%$ e $44 \%$ nessas mesmas respectivas datas; e na região Sul, a $11 \%$ e $35 \%$.

Se indicadores mostram uma melhoria desde 2004 até 2013, devido à mudança na política social e política de saneamento, após 2015, no Brasil, a situação do saneamento vem se agravando novamente, a ponto de, na organização do evento internacional Fórum Mundial da Água, inúmeros movimentos sociais se articularem na construção do Fórum Mundial Alternativo da Água (Fama). Estas articulações têm produzido reflexões e propostas que passam pela ampliação da garantia da água como direito humano, da água como bem comum, por um lado, e como um contraponto da intenção do governo atual em promover a privatização do setor e mercantilização da água no País.

Urge também reconhecer que os grandes projetos de desenvolvimento regional e nacional, apesar de reconhecidamente importantes para o desenvolvimento econômico do Brasil, no mais das vezes, agravaram enormemente as condições de vida das populações mais vulneráveis.

Altamira, no estado do Pará, por exemplo, município situado na região em que ocorreu a implantação da Usina Hidrelétrica de Belo Monte, tornou-se o mais violento entre os mais de 5.500 municípios do Brasil, segundo o Atlas da Violência, com a incrível taxa de 105,2 homicídios para cada 100 mil habitantes em 201515,16. A exemplo de outras cidades brasileiras, a violência urbana atinge preponderantemente a população jovem, pobre, negra e masculina. Ressalte-se que o inicio do aumento mais significativo da violência coincide com a aprovação do Licenciamento do empreendimento e com o início das obras ${ }^{17}$.

Além dos homicídios, pesquisas de mestrado e doutorado sobre casos de municípios nas regiões de grandes empreendimentos, como as Usinas de Santo Antonio e Jirau no Rio Madeira no estado de Rondônia e Usina Belo Monte no Rio Xingu no estado do Pará, têm mostrado inúmeros impactos diretos e indiretos na saúde humana.

Entre os impactos urbanos e na saúde, que consideram os determinantes sociais e ambientais do processo saúde-doença, registrados na literatura, citamos: o aumento populacional e fluxo migratório, espraiamento urbano, aumento da demanda por moradia, aumento no preço da terra e da moradia, aumento no número de remoções e atingidos, aumento de acidentes de trânsito, aumento da incidência de doenças sexualmente transmissíveis DST/Aids, aumento da prostituição geral e infanto-juvenil, aumento do custo de vida local, aumento do comércio e consumo de drogas e bebidas alcoólicas, aumento da incidência de gravidez na adolescência, aumento das doenças hidrotransmissíveis, proliferação de doenças infecciosas e parasitárias, aumento da exposição a metais pesados, aumento na geração de resíduos sólidos, aumento dos conflitos sociais, exclusão social, aumento da demanda por saneamento ambiental, impactos nos meios de subsistência dos povos tradicionais e na segurança alimentar, perdas de elementos da cultura local, expulsão de populações indígenas de suas terras originárias, mudanças nos hábitos alimentares, aumento da obesidade, aumento da poluição das águas, solo e ar, aumento da emissão de gases de efeito estufa, aumento nos acidentes de trabalho, aumento dos problemas de saúde mental, entre eles estresse, depressão e suicídio ${ }^{\mathbf{1 8}-20}$.

É plausível considerar que essa monta impressionante de problemas, questões e desafios, repita-se, com algumas variações, em outras regiões no interior do Brasil, palco da implantação dos chamados 'grandes projetos de desenvolvimento', como indústrias extrativas e de mineração, grandes obras de rodovias e ferrovias, usinas hidrelétricas 
e outros projetos de energia, transportes ou exploração de commodities. Ainda a respeito do impacto de grandes obras, na RMSP, vale mencionar o rastro de destruição socioambiental que ficou conhecido como 'filhos do Rodoanel'21.

Todos esses fatores ocasionam impactos urbanos, ambientais, sociais, econômicos, na vida das pessoas e no sistema de saúde. Parte significativa desses problemas, efeitos e impactos não tem sido enfrentada de forma satisfatória por meio dos instrumentos conhecidos como Estudo de Impacto Ambiental (EIA), Relatório de Impacto Ambiental (Rima), Licenciamento Ambiental e Plano Diretor.

Diante desses desafios, diversos ativistas ligados ao setor saúde têm defendido o uso da metodologia de Avaliação de Impacto à Saúde como mais uma ferramenta específica que auxilie e fortaleça o diagnóstico e compreensão dos diversos impactos gerados por projetos, programas e políticas públicas, a partir de uma abordagem dos determinantes socioambientais do processo saúde doença, principalmente considerado que os processos de avaliação de impacto ambiental e licenciamento ambiental não têm sido capazes de captar aspectos tanto gerais quanto específicos da saúde humana ${ }^{\mathbf{1 5}, \mathbf{2 2}}$.

Quando, em 2014 e 2015, a crise econômica, adiada pelos investimentos em grandes obras de construção civil e desoneração tributária a indústrias, tornou-se incontornável, a maior parte da população trabalhadora, favorecida pelas políticas de inclusão pelo consumo, é a mais atingida. Se as reformas pró-cidadania e justiça social foram adiadas - nas esferas fundiária, de mobilidade, de saneamento, e meio ambiente - a partir de 2016, um conjunto de outras reformas - corte de gastos em saúde e educação, terceirização, trabalhista, previdência, Medida Provisória 759 - dá a entender que a tragédia urbana brasileira vai se aprofundar e, agora, de forma ainda mais radical diante da ruptura com a democracia.
Considerando as forças que dirigem o processo pós-impeachment de desmanche do ainda parco bem-estar social, de entrega de patrimônios públicos e de manutenção de privilégios, podemos esperar um cenário análogo ao dos anos 1980: pauperização, concentração de renda no topo da pirâmide, crescimento de favelas, aumento de pessoas em situação de rua, aumento da violência, sobretudo contra mulheres e jovens negros. Tais tendências já se verificam em estudo recente do Instituto de Estudos Socioeconômicos (Inesc) ${ }^{\mathbf{2 3}}$.

\section{Apontamentos pela construção so- cial de um projeto para as cidades do Brasil}

De saída, é fundamental lembrar que estamos em um Brasil urbano. No último censo do Instituto Brasileiro de Geografia e Estatística (IBGE) ${ }^{\mathbf{2 4}}$, entre 190 milhões de brasileiras e brasileiros, 160 milhões moravam em cidades, isto é, $84 \%$ do total. Todas as grandes mazelas urbanas vividas pela maioria da sociedade estão ligadas à produção do espaço urbano sob a forma hegemônica da mercadoria: segregação, dispersão, periferização, carência de serviços, epidemias decorrentes da ausência de drenagem ou terrenos abandonados, violência, longas viagens diárias, ausência de áreas verdes, ocupação de áreas com risco de desmoronamento, impermeabilização exagerada do solo, enchentes, poluição de recursos hídricos, ocupação de áreas ambientalmente frágeis, desmatamento, entre outras.

Um projeto coletivo deve mostrar em que medida a prioridade dada aos negócios com o solo urbano tem nos levado a uma modernização regressiva de aspectos múltiplos. Será necessário construir bases sociais sólidas junto das quais possamos defender uma outra prioridade, a saber, o urbano como lugar favorecido do acesso aos bens e direitos fundamentais, da superação da desigualdade estrutural e da 
participação direta nas decisões coletivas, aquelas que tocam todas e todos, porque dizem respeito à vida em comum.

Para tanto, ao contrário do que se pode pensar, não faltam planos, não faltam leis e não falta competência técnica. De fato, toda cidade brasileira com mais de 20 mil habitantes tem Plano Diretor, que é obrigatório pelo art. $182,81^{\circ}$ da Constituição Federal, ou pelo Estatuto da Cidade (Lei ${ }^{\circ}$ 10.257/2001). Plenos de boas intenções, os Planos Diretores têm implementação discriminatória: aquilo que contraria os interesses dominantes, em especial relacionados com o rentismo fundiário e com o mercado imobiliário, não é implementado 25,26. Os Planos Diretores não orientam, de modo geral, o investimento público nem as principais ações do Estado no território. É muito comum que o investimento em obras contrarie a orientação de crescimento urbano dada pelo Plano Diretor. Constata-se, portanto, que o grande problema não está na ausência de novas leis, mas muito mais na aplicação das existentes.

Devemos exigir de executivos e legislativos municipais, Promotores, Juízes e Desembargadores o reconhecimento da precedência dos direitos urbanos, que se fundamentam na função social da cidade e da propriedade - previstos na CF 88 e no Estatuto da Cidade (Lei ${ }^{\circ}$ 10.257) - sobre os patrimônios privados ociosos improdutivos. Será necessária uma campanha nacional que cobre o cumprimento dessas leis urbanísticas.

Os Planos Diretores devem ser orientados pela realidade social, econômica, territorial e ambiental, definidos não apenas pela participação social, mas também por indicadores que dão a conhecer os problemas e as necessidades sociais. Por exemplo, a Pesquisa Origem-Destino deve definir o investimento na área da mobilidade urbana, e não o interesse de empreiteiras ou capitais imobiliários.

Tais Planos são complementados por Leis de Uso e Ocupação do Solo, Leis de Parcelamento do Solo, Códigos de Edificações e Legislação ambiental. Já mencionamos neste texto o conjunto de leis federais recentes que compõem um arcabouço muito avançado, mas frequentemente desconhecido pelos Executivos e Legislativos Municipais ${ }^{27}$ ou pelo Ministério Público e Judiciário ${ }^{28}$. O caso mais extravagante pode ser encontrado nos loteamentos fechados, denominados convenientemente de condomínios horizontais, nos quais o produto vendido é o lote, a não a construção. Estes são regidos pela Lei Federal $n^{\circ}$ 6.766, de 1979, e implicam a doação das ruas e áreas verdes e institucionais ao poder público municipal. No entanto, muros extensos e guaritas policiadas, em todo o Brasil urbano, impedem cidadãs e cidadãos de usarem as ruas (que são públicas) e as áreas verdes (públicas) ou institucionais.

Eventualmente, pode-se propor alguma nova lei, como é o caso da formulação do Sistema Unificado da Mobilidade Urbana (Sumu) ou do Sistema do Desenvolvimento Urbano (SDU), que, a exemplo do Sistema Único de Saúde (SUS), pretendem definir atribuições mais claras para cada um dos entes federativos. Além disso, o Estatuto da Metrópole, promulgado em 2015, poderia ser um exemplo de lei que veio para resolver o óbvio problema da falta de integração entre municípios e entre municípios e Estados no planejamento e gestão de Regiões Metropolitanas.

Deve ser recuperado o protagonismo dos municípios - isoladamente e integrados em regiões metropolitanas ou núcleos - e dos cidadãos nos destinos das cidades. Os investimentos - finalidade e localização - devem estar subordinados aos indicadores de vulnerabilidade social e ambiental e, ainda, ao controle social, de modo a afastar a influência dos lobbies privados ligados ao rentismo imobiliário e aos financiamentos de campanha eleitoral. Para tanto, os canais da democracia representativa e da participação são necessários, mas não suficientes. É preciso retomar um processo capilarizado territorialmente de formação de cidadãos informados sobre as cidades, seus problemas e seus direitos. 
Fortalecer o governo local, mais próximo do território, pode ser providencial na implementação de políticas públicas mais atentas à diversidade das necessidades habitacionais e, ainda, no que tange aos diferentes portes e características geográficas e ambientais de cada cidade. Este é um consenso mínimo: a política habitacional precisa superar o pensamento único fixado nos grandes conjuntos, no mais das vezes distante do tecido urbano. Já está claro que são necessárias linhas programáticas capazes de atender às demandas por urbanização, regularização e integração de assentamentos precários, além da promoção da locação social e da produção de unidades, com valorização da autogestão e da Assistência Técnica. Em alguma medida, tais pontos vêm sendo consensuados no Plano Nacional de Habitação (2009) e na recente carta do Conselho e do Instituto de Arquitetos do Brasil (2018). Este último reforça a importância de estruturar a política habitacional de modo coordenado com a política de mobilidade, com governança inovadora e democratização na gestão de territórios.

Outros apontamentos são dignos de nota. Se está evidente que o rodoviarismo é um paradigma inviável e falido, é preciso defender de uma vez por todas a prioridade ao transporte coletivo eficiente e integrado, além do fomento dos meios de transporte não motorizados e à mobilidade ativa. Para isso, temos a Lei Federal da Mobilidade Urbana - $\mathrm{n}^{\mathrm{o}}$ $12.587 / 2012$.

Da mesma forma, é inadiável promover o saneamento ambiental garantindo a universalidade de bens básicos à vida digna, saudável e segura como o acesso à água potável, esgoto, drenagem e coleta de resíduos sólidos (Lei federal do saneamento Básico $\mathrm{n}^{\mathrm{o}} 11.445 / 2007$ e Lei federal dos Resíduos Sólidos $\mathrm{n}^{\mathrm{o}}$ 12.305/2010). Atualmente, reverter esse quadro exige a abordagem de práticas ambientalmente responsáveis de captação, distribuição, uso e reuso da água, além de descarte do esgoto. $\mathrm{O}$ mesmo deve ser feito com os resíduos sólidos, fonte de emprego e riqueza, que devem obedecer aos ciclos da redução do consumo, reuso e reciclagem. Para completar as ações públicas na urbanização das periferias insalubres, invisíveis, ilegais e abandonadas pelo Estado, é preciso levar até elas o serviço de arquitetos, engenheiros, advogados e assistentes sociais por meio da Assistência Técnica, conforme Lei Federal $n^{\circ}$ 11.888. Desse modo, levar segurança jurídica e combate à insalubridade habitacional nas áreas de alta densidade de ocupação.

Os projetos e investimentos urbanos de requalificação, projetos viários, ferroviários, obras de usinas de geração de energia, projetos de mineração a agronegócio precisam incorporar um critério de justiça territorial. Segundo esse critério, por exemplo, todos os projetos de desenvolvimento local, regional ou nacional têm que garantir a melhoria das condições de vida dos residentes do entorno que certamente são e serão atingidos e sofrem inúmeros impactos tangíveis e intangíveis. Nesse sentido, por exemplo, nenhuma família poderia ser removida para uma condição inferior em temos de qualidade e de localização da moradia em função de um projeto de desenvolvimento. Um projeto de desenvolvimento para os países que, do ponto de vista local, aprofunde desigualdades, iniquidades e promova injustiças mereceria a reprovação dos setores e segmentos compromissados com o princípio da dignidade humana.

Esses são temas conhecidos cuja defesa vai exigir ânimos renovados nesse ciclo que se abre. Assim como a proteção efetiva das reservas hídricas, de Área de Preservação Permanente, Área de Preservação de Mananciais, mangues e dunas; a proteção efetiva e despoluição de cursos de água; a cidade de uso misto e compacta bem como ampliar áreas verdes e a arborização dos espaços de uso coletivo. Ademais, a esses tópicos conhecidos, será necessário integrar temas mais recentes, como a agricultura urbana, soberania alimentar e ligados à saúde pública. As lutas e planos urbanos devem se articular às lutas camponesas, 
especialmente na defesa da agricultura familiar e da agroecologia.

Uma nova agenda para as cidades no Brasil deve incorporar a produção social da saúde como um critério para a tomada de decisões sobre investimentos públicos e privados, considerando a priorização dos grupos historicamente vulneráveis do nosso país, como: populações pobres, mulheres, crianças, jovens, idosos, pessoas com deficiências, negros, indígenas, caiçaras, Lésbicas, Gays, Bissexuais, Transsexuais, Queer e Intersexuais.

Também cabe a nós compreender como se dá, nas cidades, o nó estrutural entre desigualdades de classe, raça e gênero. Isto para sabermos ouvir as vozes dos personagens que entram em cena e protagonizam um novo ciclo de lutas: do movimento negro, dos feminismos, dos coletivos artísticos das periferias, da cultura emergente de apropriação dos espaços públicos e dos secundaristas, cuja disposição e irreverência surpreenderam a todos ${ }^{29}$. Ainda que enfrentem adversidades específicas, esses atores coletivos têm pontos em comum: são comunidades políticas que clamam pela efetivação de direitos sociais e políticos, por formas inclusivas de sociabilidade e modos mais horizontais de decisão, pela cidade como arena de participação de todas e todos, como lugar do uso e do encontro.

\section{Considerações finais}

Um projeto como o que brevemente apresentamos acima não terá capacidade de implementação apenas pela clareza de sua formulação intelectual. A construção social de uma agenda para as cidades não pode deixar de prever a convergência do conhecimento teórico-crítico, dos saberes técnico-profissionais e dos movimentos sociais. Por isso, a construção social será tripartite. O conhecimento técnico e o teórico-crítico permitem aprofundar temas complexos e desenvolver mais detalhadamente uma agenda para as cidades, no curto, no médio e no longo prazo. Todavia, a força social necessária à implementação desse projeto vem do protagonismo dos movimentos sociais, sindicatos, centros acadêmicos, coletivos diversos, em especial aqueles participantes da democracia direta. Já temos muitos desses situados em escolas, igrejas, centros comunitários. Como já nos ensinara Paulo Freire ${ }^{30}$, o conhecimento pode ser um instrumento de libertação. Formular diagnósticos e propostas para as cidades com adesão popular é um grande desafio e ajudará a combater a massacrante dominação ideológica protagonizada pela grande mídia e em discursos oficiais conservadores. As universidades têm o papel fundamental de produzir pesquisas implicadas e, ainda, cursos e projetos de extensão acadêmica que incidam na realidade. Com isso, evitamos também o risco secular de alienação do pensamento colonizado, ainda existente em parte das nossas universidades.

Já está claro que, para realizarmos essas latências, será necessário assumirmos um projeto coletivo e pactuado, com capilarização, presença na opinião pública e base social, estruturado nessa cooperação entre movimentos sociais, universidades, entidades técnicas e profissionais.

\section{Colaboradores}

Maricato E, Colosso P, Comarú FA contribuíram para a concepção, análise, planejamento e interpretação dos dados contidos no artigo. 


\section{Referências}

1. Stiglitz J. O preço da desigualdade. Lisboa: Bertrand; 2013

2. Piketty T. O capital no século XXI. Rio de Janeiro: Intrínseca; 2014.

3. Pochmann M. Brasil sem industrialização: a herança renunciada. Ponta Grossa: UEPG; 2016.

4. Maricato E. Metrópole na periferia do capitalismo. São Paulo: Hucitec; 1996.

5. Andrade CM, Bonduki N, Rossetto R, editores. Arquitetura e habitação social em São Paulo 19891992. São Paulo: USP; 1993.

6. Organização das Nações Unidas para a Alimentação e Agricultura. Brasil desapareceu do mapa da fome como resultado da decisão política. FAO [internet]. 2014 out 13 [acesso em 2018 set 26]. Disponível em: http://www.fao.org/americas/noticias/ ver/pt/c/260599/.

7. Mercadante A, Zero M. Governos do PT: um legado para o futuro. São Paulo: Fundação Perseu Abramo; 2018.

8. UQBAR. Anuário 2016: securitização e financiamento imobiliário [internet]. Rio de Janeiro: UQBAR; 2016 [acesso em 2018 set 26]. Disponível em: http://www.uqbar.com.br/institucional/oque/anuarios.jsp.

9. Maricato E, Royer L. A política urbana e de habitação. In: Maringoni G, Medeiros J. Cinco mil dias: o Brasil na era do lulismo. São Paulo: Boitempo; 2017. p. 147-165.

10. Associação Nacional de Transporte Público. Sistema de Informações da Mobilidade Urbana da Associação Nacional de Transportes Público - Simob/ ANTP. São Paulo: ANTP; 2018 [acesso em 2018 set 26]. Disponível em: http://files.antp.org.br/simob/ simob-2016-v6.pdf.
11. Miraglia SGK, Silva CBP. Quanto custa viver nas metrópoles. In: Saldiva P. Meio ambiente e saúde: o desafio das metrópoles. São Paulo: Ex-Libris; 2010.

12. Balazina A, Ogura AT, Kenya A, et al. Sumário de evidências: saúde, sustentabilidade e cidadania: um observatório de caso tendo como cenário a região metropolitana de São Paulo [internet]. São Paulo: Instituto Saúde e Sustentabilidade; 2009 [acesso em 2018 set 26]. Disponível em: https://www.saudeesustentabilidade.org.br/sumario_de_evidencias. pdf.

13. Szwarc A, Vasconcellos EA, Branco GM, et al. Mobilidade sustentável: realidade e desafios. In: Saldiva P. Meio ambiente e saúde: o desafio das metrópoles. São Paulo: Ex- Libris; 2010.

14. Brasil. Instituto de Pesquisa Econômica Aplicada. Relatório Brasileiro para o Habitat III. Brasília, DF: Ipea; 2016 [acesso em 2018 set 26]. Disponível em: http://habitat3.org/wp-content/uploads/National-Report-LAC-Brazil-Portuguese.pdf.

15. Brasil. Ministério da Saúde. Avaliação de Impacto à Saúde - AIS: metodologia adaptada para aplicação no Brasil. Brasília, DF: Ministério da Saúde; 2014.

16. Brasil. Instituto de Pesquisa Econômica Aplicada. Atlas da violência 2017. Brasília, DF: Ipea; 2017.

17. Souza DP. Avaliação de impacto à saúde: estudo da Usina Hidrelétrica de Belo Monte e uma análise sobre a violência em Altamira - PA [dissertação]. Santo André: Universidade Federal do ABC; 2018.

18. Abe KC. Análise da metodologia de avaliação de impacto à saúde no brasil com enfoque a grandes empreendimentos e políticas públicas [tese]. São Paulo: Universidade Federal de São Paulo; 2017.

19. Fragelli IKZ, Oliveira LSS. Considerações sobre os impactos em saúde, no contexto do deslocamento forçado de ribeirinhos em Belo Monte. In: Magalhães SB, Cunha MC, organizadores. A Expulsão de 
Ribeirinhos em Belo Monte: Relatório da SBPC [internet]. São Paulo: SBPC; 2017 [acesso em 2018 set 26]. p. 203-234. Disponível em: http://portal.sbpcnet.org.br/livro/belomonte.pdf.

20. Silveira M, Araujo Neto MD. Licenciamento ambiental de grandes empreendimentos: conexão possível entre saúde e meio ambiente. Ciênc Saúde Colet. 2014; 19(9):3829-3838.

21. Akerman M, Maymone CC, Bógus C, et al. As novas agendas de saúde a partir de seus determinantes sociais. In: Galvao LAC, Finkelman J, Henao S, organizadores. Determinantes Sociais e Ambientais da Saúde. Washington: OPAS; 2011. p. 56-68.

22. Bhatia R. Health Impact Assessment: A Guide for Practice. Oakland: Human Impact Partners; 2011.

23. Instituto de Estudos Socioeconômicos. Direitos Humanos em tempos de austeridade. Brasília, DF: Inesc; 2017 [acesso em 2018 set 26]. Disponível em: http://www.inesc.org.br/noticias/biblioteca/publicacoes/outras-publicacoes/direitos-humanos-em-tempos-de-austeridade/view.

24. Instituto Brasileiro de Geografia e Estatística. Censo 2010. Rio de Janeiro: IBGE; 2010 [acesso em 2018 set 26]. Disponível em: https://censo2010.ibge.gov. $\mathrm{br} /$.
25. Maricato E. As ideias fora do lugar e o lugar fora das ideias. Planejamento urbano no Brasil. In: Arantes O, Vainer C, Maricato E. A cidade do pensamento único: Desmanchando consensos. Petrópolis: Vozes; 2000.

26. Villaça F. As Ilusões do Plano Diretor. São Paulo: Edição do Autor; 2005.

27. Denaldi R. Políticas de urbanização de favelas: evolução e impasses [tese]. São Paulo: Universidade de São Paulo; 2003.

28. Bedeschi L. Regularização Fundiária como diretriz de recuperação ambiental em áreas de preservação permanente [dissertação]. São Paulo: Pontifícia Universidade Católica de São Paulo; 2012.

29. Colosso P. Rem Koolhaas nas metrópoles delirantes: entre a Bigness e o big business. São Paulo: Annablume; 2017.

30. Freire P. A Pedagogia da autonomia. Rio de Janeiro: Paz e Terra; 1996.

Recebido em 31/07/2018

Aprovado em 09/09/2018

Conflito de interesses: inexistente

Suporte financeiro: não houve 